\title{
Analisis Performa Artificial Hip Joint untuk Posisi Rukuk dalam Gerakan Salat dengan Menggunakan Teknik FSI (Fluid-Structure Interaction)
}

\author{
Mohammad Tauviqirrahman*, Rifky Ismail, Rifky Ardiansyah Budiman \\ Departemen Teknik Mesin, Fakultas Teknik, Universitas Diponegoro \\ J1. Prof. Sudharto, SH., Tembalang-Semarang 50275, Telp. +62247460059 \\ *E-mail: mtauviq99@gmail.com
}

\begin{abstract}
The users of artificial hip joint are recommended by doctors to limit the extreme movements that can damage the artificial hip joint. The examples of the movements are squat, run and Islamic prayer (salat). All this time, the researches of artificial hip joint tend to ignore the existence of joint lubricating fluid, i.e. synovial fluid. The main objective of this research is to analyze the influences of synovial fluid on the characteristics of lubrication and the structure of artificial hip joint. In this research, bowing (i.e. rukuk) during salat is of particular interest. The simulation is performed based on the the bipolar type model of artificial hip joint using the finite element method in solid components and fluid-structure interaction (FSI) in fluid components to define the influence on one another components to the hydrodynamic pressure, deformation, and von Mises stress. The simulation results show that the risks of impingement of artificial hip joint during bowing are very small. In addition, based on the simulation, it is found that the existence of synovial fluid has significant effect on the performance of artificial hip joint, so it cannot be ignored.
\end{abstract}

Keywords: artificial hip joint, bowing, fluid-structure interaction, salat movements, synovial fluid

\section{Abstrak}

Pengguna sendi tulang panggul buatan (artificial hip joint) disarankan oleh para dokter untuk membatasi gerakan ekstrim yang dapat merusak hip joint buatan. Gerakan tersebut misalnya jongkok, berlari, dan salat. Selama ini, penelitian tentang artificial hip joint cenderung tidak menyertakan keberadaan cairan pelumas sendi, yaitu synovial fluid. Penelitian ini bertujuan untuk menganalisis pengaruh synovial fluid pada hip joint terhadap karakteristik pelumasan, serta struktur dari artificial hip joint tersebut. Yang menjadi fokus dalam penelitian ini adalah gerakan salat berupa rukuk. Simulasi ini dilakukan pada model artificial hip joint jenis bipolar dengan menggunakan metode elemen hingga pada komponen solid dan fluid-structure interaction (FSI) pada komponen fluid untuk mendefinisikan pengaruh satu sama lain antara kedua komponen terhadap tekanan hidrodinamik, deformasi dan tegangan von Mises. Dari hasil simulasi didapatkan bahwa gerakan rukuk memiliki deformasi yang relatif cukup kecil jika dibandingkan dengan toleransi (clearance) yang ada, sehingga resiko impingement sangat kecil. Selain itu, dari hasil simulasi juga dibuktikan bahwa keberadaan synovial fluid memiliki pengaruh yang signifikan terhadap performa artificial hip joint, sehingga tidak bisa diabaikan.

Kata kunci: sendi panggul buatan; rukuk; fluid-structure interaction; gerakan salat; synovial fluid

\section{Pendahuluan}

Hip joint (sendi panggul) merupakan sendi yang penting dalam sistem anatomi manusia. Sendi ini terletak diantara pinggul dan pangkal tulang paha yang menghubungkan tulang paha dan tulang pelvis, dan menjadikannya tumpuan beban paling besar (weight bearing). Hip joint terdiri dari tiga bagian utama, yaitu femur, femoral head dan cup socket.

Gaya hidup masyarakat masa kini yang cenderung tidak sehat dan kurangnya kewaspadaan menjadi sebab utama terjadinya berbagai macam gangguan pada sendi tulang. Pada kondisi yang sudah serius, nyeri dan berbagai macam penyakit pada hip joint dapat mengakibatkan penderitanya mengalami kesulitan menggerakkan kaki, bahkan kesulitan untuk dapat berjalan. Kerusakan permanen pada hip joint akibat proses pengapuran, penuaan atau kecelakaan memerlukan tindakan penggantian dengan artificial hip joint. Menurut Kiefer [1], di negara-negara maju jumlah pasien yang menggunakan artificial hip joint sangat tinggi. Saat ini, para dokter menyarankan untuk membatasi gerakan pada pasien yang mengunakan artificial hip joint agar tidak terjadi kerusakan pada artificial hip joint. Gerakan tersebut misalnya jongkok, berlari dan beberapa gerakan dalam salat.

Penelitian yang dilakukan Legowo [2] mengevaluasi acetabular liner dan femoral head pada artificial hip joint model UNDIP dalam perbandingan dengan model Kluess, dkk [3]. Sedangkan Dhaneswara [4] telah melakukan penelitian tentang pengaruh cleareance terhadap keausan dan impingement (tubrukan) saat melakukan gerakan salat pada artificial hip joint model UNDIP jenis bipolar menggunakan metode elemen hingga. Gapa [5] juga melakukan 
penelitian yang mengobservasi gerakan berjalan dan salat pada hip joint dengan menggunakan analisis statik, serta mencari gaya reaksi yang terjadi saat melakukan gerakan salat. Analisis yang lebih detil telah dilakukan oleh Saputra dkk. [6]. Mereka membandingkan performa sambungan tulang panggul buatan untuk dua jenis kegiatan: Western style dan Japanese style.

Penelitian-penelitian tersebut, meskipun demikian, hanya menfokuskan pada analisis struktur solid (disebut dry contact), tanpa adanya cairan pelumas yang terdapat pada celah komponen-komponen penyusun sambungan tulang panggul tersebut. Padahal dalam kenyataannya, cairan pelumas berupa synofial fluid yang terbentuk secara alami dalam tubuh akan memiliki pengaruh yang cukup signifikan dalam performa sambungan tulang panggul buatan [7-11]. Dengan kata lain, asumsi dry contact dalam analisis sambungan tulang panggul buatan menjadi kurang valid dan bisa menjurus kepada penarikan kesimpulan hasil penelitian yang salah.

Penelitian ini merupakan penelitian lanjutan dari penelitian sebelumnya [2,4-6,11] dimana parameter tentang adanya synovial fluid akan dipertimbangkan sehingga pemodelan artificial hip joint menjadi lebih realistis. Synovial fluid merupakan cairan pelumas pada sendi dan terdapat diantara tempurung (inner liner cup) dan kepala (femoral head) dari hip joint. Penelitian ini memiliki tujuan untuk menganalisis pengaruh keberadaan synovial fluid terhadap karakteristik pelumasan (shear stress), serta struktur dari artificial hip joint tersebut (deformasi, tegangan von Mises) untuk gerakan rukuk sebagai bagian dari kegiatan salat. Dengan penelitian ini diharapkan selain dapat membantu pengguna dalam aktivitas sehari-hari, juga memastikan bahwa artificial hip joint buatan tidak akan mengalami deformasi yang berlebihan yang dapat mengakibatkan tubrukan dan dislokasi saat digunakan untuk melakukan gerakan salat.

\section{Metode penelitian}

Penelitian memanfaatkan perangkat lunak untuk dua jenis simulasi; (1) simulasi struktur berbasis metode elemen hingga untuk analisis komponen solid, dan (2) simulasi fluida berbasis metode volume hingga untuk analisis karakteristik synofial fluid. Kedua analisis ini kemudian dikombinasikan dengan teknik fluid-structure interaction (FSI) menggunakan system coupling untuk mendefinisikan pengaruh satu sama lain antara kedua komponen terhadap tekanan hidrodinamik, deformasi dan tegangan von Mises. Gambar 1 menunjukkan skema fluid-structure interaction pada perangkat lunak yang digunakan.

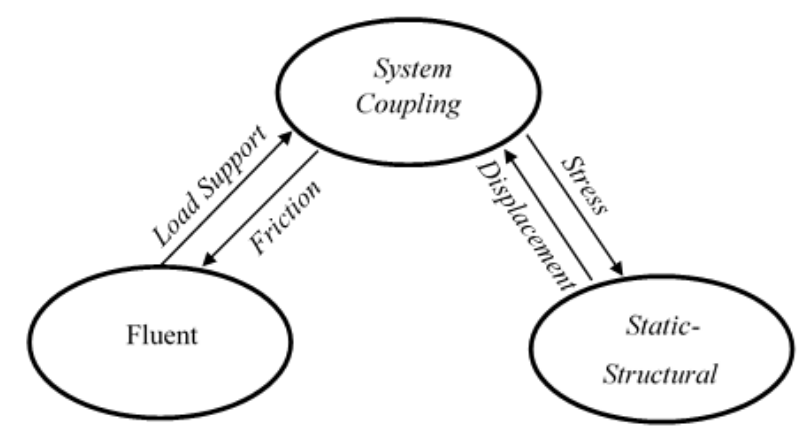

Gambar 1. Teknik fluid-structure interaction (FS) pada perangkat lunak

\subsection{Pemodelan Geometri Artificial Hip Joint}

Dalam penelitian ini, artificial hip joint terdiri dari poros head yang berputar secara spherical terhadap housing cup. Kedua permukaannya terpisah oleh lubrikan. Tekanan tinggi terbentuk karena adanya efek wedge yang berguna untuk men-support muatan pada poros yang berputar. Karena terdapat gaya yang terjadi akibat gerakan sholat, tekanan maksimum juga akan meningkat. Tekanan maksimum juga terpengaruh dengan viskositas lubrikan. Secara lengkap, skema artificial hip joint ditunjukkan dalam Gambar 2.

Kasus simulasi dalam penelitian ini mengaplikasikan dua permukaan yang memiliki kondisi batas no-slip. Selain itu pada kasus ini juga diteliti apakah gaya fluida (synofial fluid) memberikan pengaruh terhadap deformasi head maupun cup yang cukup signifikan atau tidak. Geometri yang digunakan pada kasus ini ditunjukkan dalam Tabel 1 di bawah.

Tabel 1. Data Geometri.

\begin{tabular}{lccc}
\hline \multicolumn{1}{c}{ Geometri } & Simbol & Dimensi & Satuan \\
\hline Panjang batang stem & $L$ & 32 & $\mathrm{~mm}$ \\
Jari-jari batang stem & $r_{B}$ & 7.05 & $\mathrm{~mm}$ \\
Jari-jari head & $r$ & 14 & $\mathrm{~mm}$ \\
Jari-jari dalam cup & $R$ & 14.1 & $\mathrm{~mm}$ \\
Radial clearance & $C$ & 0.1 & $\mathrm{~mm}$ \\
Tebal cup & $H_{r}$ & 6.9 & $\mathrm{~mm}$ \\
\hline
\end{tabular}




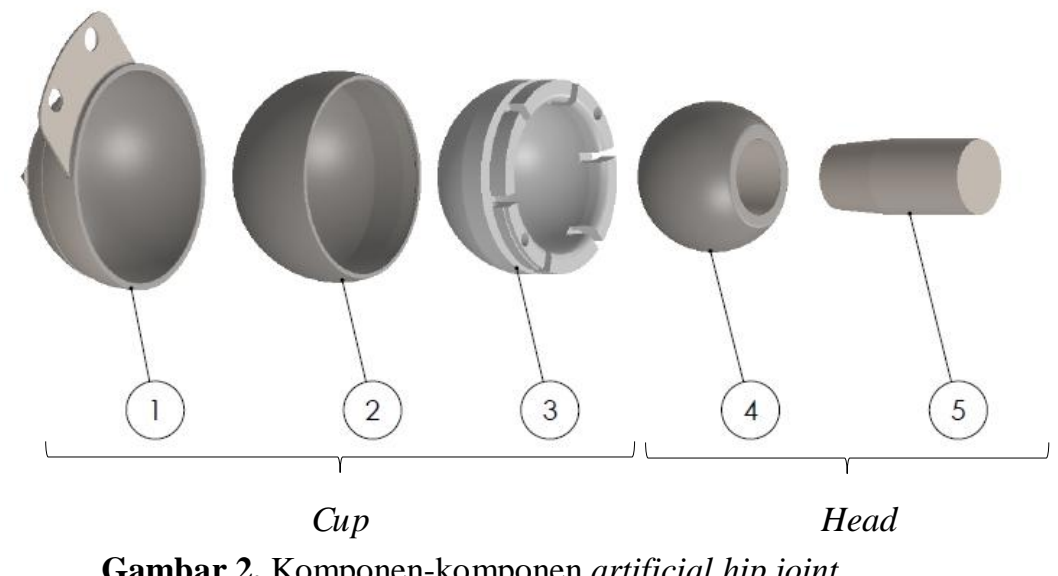

(Catatan: 1. Acetabular Cup, 2. Outer Liner, 3. Inner Liner, 4. Femoral Head, 5. Batang Stem).

Dari posisi normal hip joint atau disebut juga posisi anatomi (posisi berdiri), sudut untuk pemodelan geometri diperoleh dengan cara memutar posisi femoral head. Dengan demikian, untuk gerakan rukuk sudutnya adalah sebagai berikut:

$\begin{array}{lll}-\quad \text { Flexion }(\text { sumbu } \mathrm{x}) & =86,3^{\circ} \\ \text { - } \quad \text { Abduction }(\text { sumbu y) } & =-2,2^{\circ} \\ \text { - } \quad \text { Rotation }(\text { sumbu z) } & =23,7^{\circ}\end{array}$

Sehingga, pemodelan geometri untuk kasus gerakan rukuk dapat dilihat dalam Gambar 3 di bawah ini.

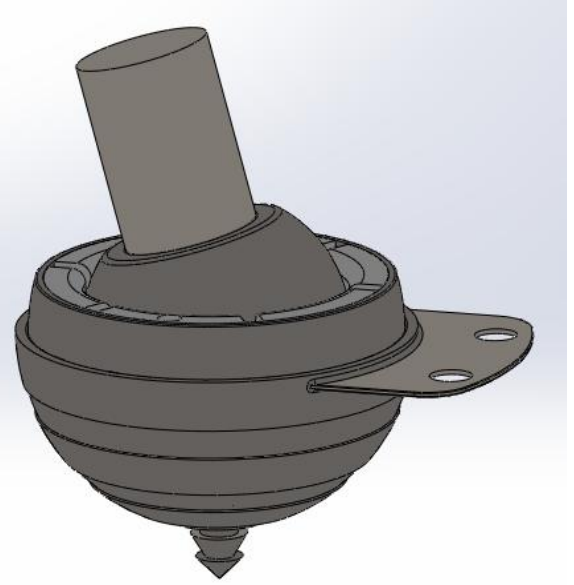

(a)

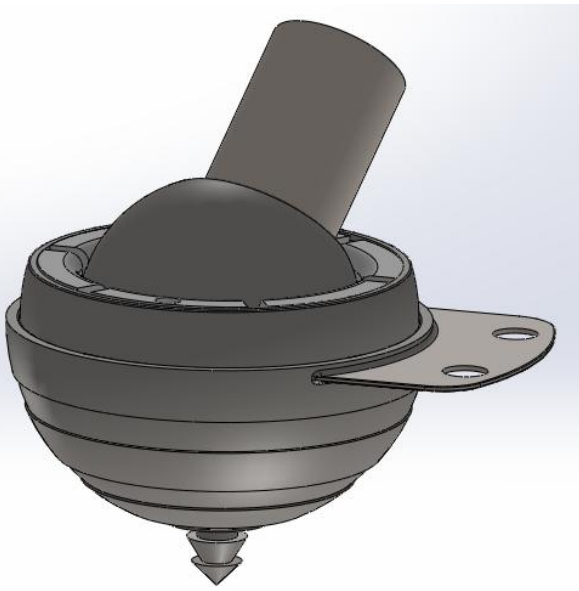

(b)

Gambar 3. Pemodelan kasus gerakan rukuk: a) posisi sebelum gerakan (posisi anatomi dalam keadaan berdiri), b) posisi saat gerakan rukuk.

\subsection{Meshing}

Dalam penelitian ini, fitur face sizing dalam perangkat lunak digunakan untuk mendapatkan kualitas mesh (elemen dan nodal) yang memenuhi standar seperti disajikan dalam Tabel 2 di bawah. Hasil meshing untuk kasus gerakan rukuk ditunjukkan pada Gambar 4. Teknik FSI ini mengharuskan proses meshing dilakukan pada dua domain komputasi, yaitu solid (komponen artificial hip joint) dan fluid (pelumas synofial fluid).

Tabel 2. Karakteristik mesh pada model hip joint dan synofial fluid

\begin{tabular}{lcc}
\hline & Domain fluida & Domain solid \\
\hline Jumlah elemen & $1,171,810$ & 614,317 \\
Jumlah nodal & 362,087 & 933,132 \\
Average Skewness & 0.30025 & 0.24528 \\
\hline
\end{tabular}



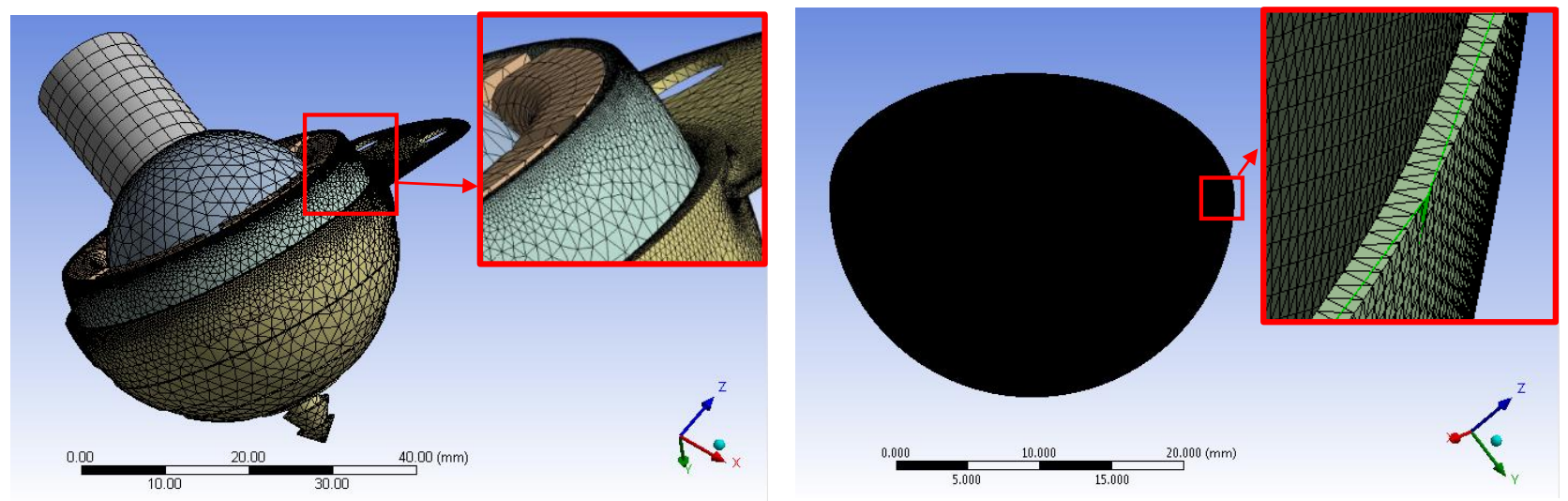

Gambar 4. Struktur mesh pada (a) domain solid, (b) domain fluid.

\subsection{Kondisi Batas pada Domain Fluid}

Pelumas synofial fluid dimodelkan sebagai fluida non-Newtonian. Pomodelan Cross dipilih untuk memodelkan sifat non-Newtonian ini, dan pelumas ini memiliki karakteristis fluida yaitu zero shear viscocity sebesar $40 \mathrm{~kg} / \mathrm{m}-\mathrm{s}$, power-law index (n) sebesar 0.27 , time constant sebesar $9.54 \mathrm{~s}$ dan massa jenis sebesar $1010 \mathrm{~kg} / \mathrm{m}^{3}$. Untuk mendefinisikan kondisi batas gerakan rukuk, maka dalam perangkat lunak pada tab Motion digunakanlah opsi Components untuk memasukkan parameter velocity components. Tabel 3 menunjukkan kondisi batas vektor kecepatan untuk gerakan artificial hip joint selama aktifitas rukuk.

Tabel 3. Hasil Perhitungan komponen kecepatan

\begin{tabular}{lccc}
\hline \multirow{3}{*}{ Gerakan } & \multicolumn{3}{c}{ Komponen Kecepatan } \\
\cline { 2 - 4 } Ruku & $\begin{array}{c}\text { Flexion }(\mathrm{X}) \\
(\mathrm{m} / \mathrm{s})\end{array}$ & $\begin{array}{c}\text { Abduction }(\mathrm{Y}) \\
(\mathrm{m} / \mathrm{s})\end{array}$ & $\begin{array}{c}\text { Rotation }(\mathrm{Z}) \\
(\mathrm{m} / \mathrm{s})\end{array}$ \\
\cline { 2 - 4 } & 0.010581 & -0.000270 & 0.002906 \\
\hline
\end{tabular}

Dalam Teknik FSI, diperlukan pendefinisian daerah kontak antara fluida dan solid dengan menggunakan dynamic mesh. Dalam penelitian ini, daerah kontak antara fluida dan solid adalah daerah pada permukaan bagian dalam cup dan permukaan bagian luar fluid, serta bagian luar head dengan bagian dalam fluid.

\subsection{Kondisi Batas pada Domain Solid}

Pendefinisian kondisi batas pada static structural yang utama adalah penentuan fixed support, yang diberikan pada bagian terluar acetabular cup agar tidak terjadi pergerakan atau perpindahan. Selanjutnya untuk mengaktifkan sistem coupling dalam fluid-solid interface (FSI) perlu penentuan daerah pada solid yang mempunyai kontak langsung dengan fluida atau synofial fluid. Daerah kontak antara fluida dan solid yaitu pada permukaan bagian dalam cup dan permukaan bagian luar fluid, serta bagian luar head dengan bagian dalam fluid.

\section{Hasil dan pembahasan}

\subsection{Performa Hidrodinamik Pelumasan}

Setelah melakukan simulasi perhitungan numerik dengan menggunakan ANSYS Fluent 16.0 dengan menggunakan metode 2-way FSI diperoleh distribusi tekanan hidrodinamik untuk gerakan rukuk, seperti yang ditunjukkan dalam Gambar 5. Berdasarkan Gambar 5 ini, terlihat bahwa artificial hip joint kaki kanan pada posisi rukuk diperoleh tekanan maksimum yaitu pada sekitar $120^{\circ}-150^{\circ}$. Gambar 6 menunjukkan distribusi tekanan pada artificial hip joint. Kontur berwarna merah menandakan tingginya tekanan dan kontur berwarna biru menandakan rendahnya tekanan. Perbedaan nilai tekanan ini disebabkan karena adanya kenaikan tekanan pada titik-titik yang terkena arah gaya reaksi selama gerakan rukuk.

\subsection{Deformasi Domain Solid}

Gambar 7 menunjukkan kontur deformasi pada hip joint pada bermacam posisi rukuk. Seperti yang ditunjukkan pada Gambar 7 ini tekanan yang diberikan synovial fluid ke inner liner cup dan femoral head cukup kuat sehingga mampu memberikan deformasi elastis. Dari Gambar 7 ini juga terlihat bahwa deformasi yang cukup besar terjadi pada saat posisi rukuk. Deformasi ini dimungkinkan disebabkan oleh gaya beban dan sudut range of motion pada saat gerakan rukuk yang cukup besar. Meskipun demikian, deformasi yang terjadi jauh lebih kecil jika dibandingkan dengan clearance yang ada sehingga tidak memungkinkan terjadinya metal-to metal contact antara inner liner cup dan femoral head. Dengan kata lain, impingement pada artificial hip joint untuk gerakan rukuk tidak akan terjadi. 


\subsection{Tegangan von Mises Domain Solid}

Gambar 8 menunjukkan kontur tegangan von Mises dimana kontur berwarna merah menandakan tingginya tegangan dan kontur berwarna biru menandakan rendahnya tegangan. Terlihat bahwa tegangan maksimum yang dihasilkan pada posisi gerakan rukuk ini relatif cukup tinggi. Hal ini dimungkinkan karena gaya beban dan sudut range of motion pada saat gerakan rukuk bernilai cukup besar akibat besarnya tekanan hydrodinamik synovial fluid.

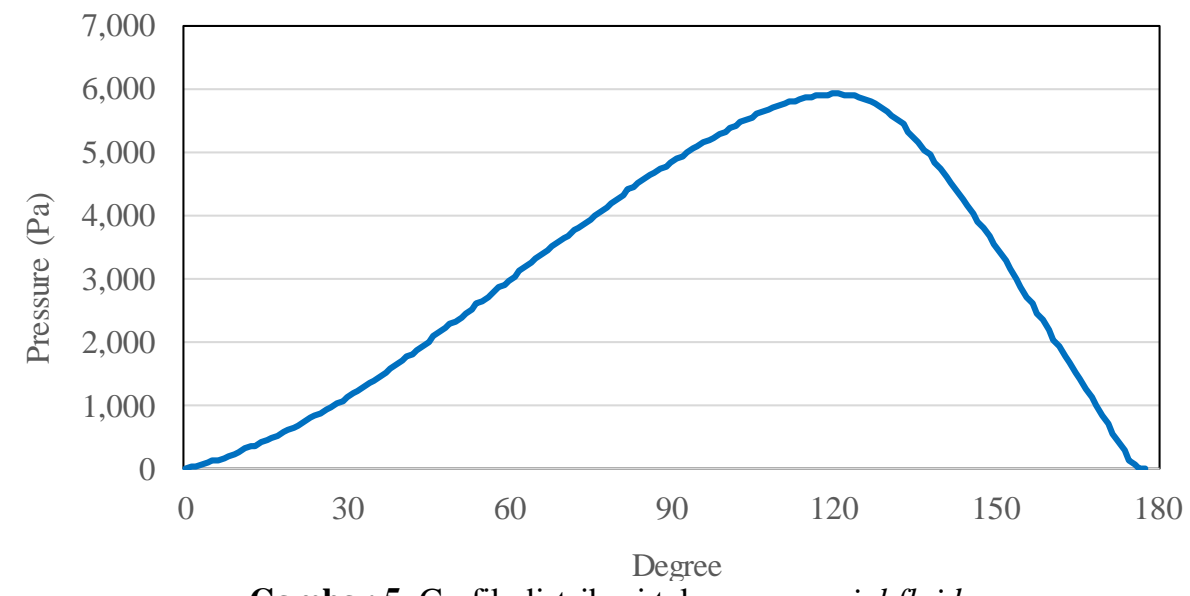

Gambar 5. Grafik distribusi tekanan synovial fluid

Apabila dibandingkan dengan penelitian yang dilakukan oleh Gapa [5] dimana pada penelitian tersebut dilakukan tanpa memperhitungkan pengaruh keberadaan synovial fluid, terdapat perbedaan nilai tegangan von Mises yang cukup signifikan dengan hasil penelitian saat ini yang memperhitungkan keberadaan synovial fluid (present study). Perbedaan nilai tegangan von Mises tersebut hingga mencapai 10 kali lipat. Penjelasan yang paling mungkin adalah bahwa perbedaan ini disebabkan karena keberadaan cairan synovial fluid diantara inner liner cup dan femoral head, yang berfungsi sebagai lubrikan dan mengurangi gesekan antara kedua komponen hip joint tersebut. Pada penelitian tanpa synovial fluid, terjadi impingement (tubrukan) pada gerakan tersebut, dimana antara batang femoral head berkontak dengan bagian inner cup, dengan tegangan maksimum terjadi pada titik kontak tersebut. Sedangkan pada penelitian dengan synovial fluid, tidak terjadi kontak antara kedua komponen tersebut sehingga tidak terjadi impingement, serta tegangan maksimum tidak terjadi pada titik yang sama (titik kontak impingement) seperti pada penelitian tanpa synovial fluid. Maka hal ini membuktikan bahwa keberadaan cairan synovial fluid memiliki pengaruh yang signifikan terhadap kinerja artificial hip joint, karena dapat mengurangi tegangan yang terjadi dan mencegah terjadinya impingement. Tabel 4 menunjukkan perbandingan prediksi tegangan von Mises antara yang mempertimbangkan synovial fluid dengan yang tidak mempertimbangkan synovial fluid.

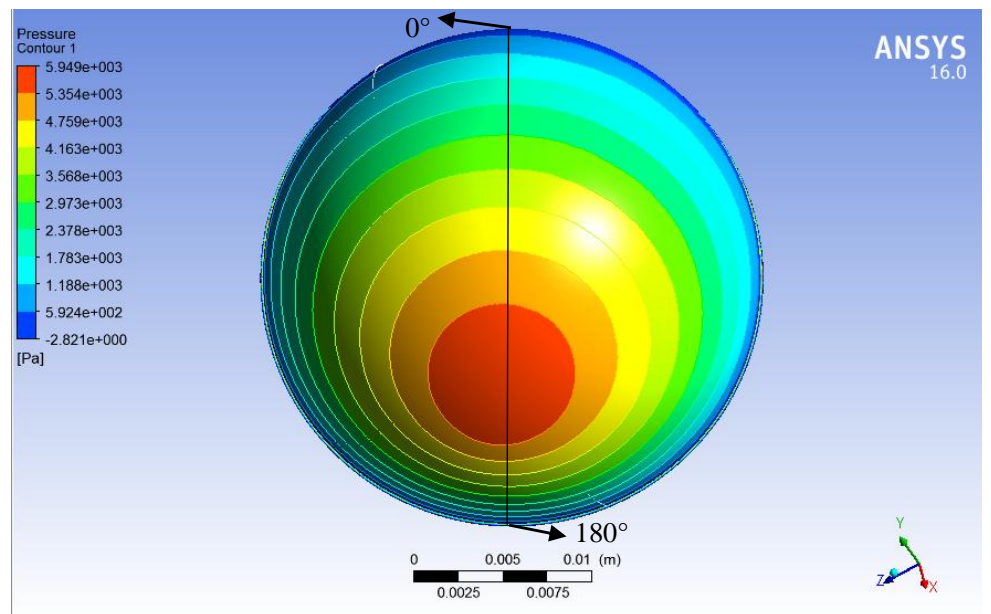

Gambar 6. Kontur tekanan pada hip joint kaki kanan

Tabel 4. Perbandingan hasil simulasi tanpa dan dengan synofial fluid

\begin{tabular}{lcc}
\hline \multirow{2}{*}{ Posisi } & \multicolumn{2}{c}{ Tegangan von Mises (MPa) } \\
\cline { 2 - 3 } Rukuk & Tanpa mempertimbangkan synofial fluid & Dengan mempertimbangkan synofial fluid \\
\cline { 2 - 3 }
\end{tabular}



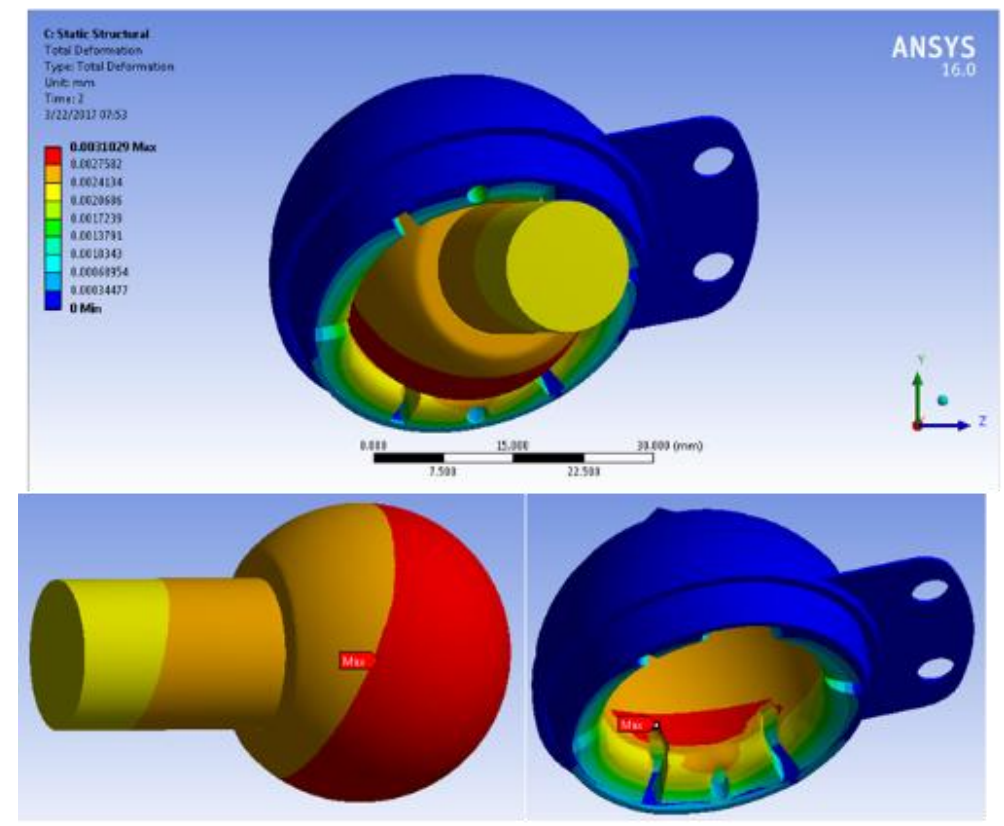

Gambar 7. Kontur deformasi pada artificial hip joint

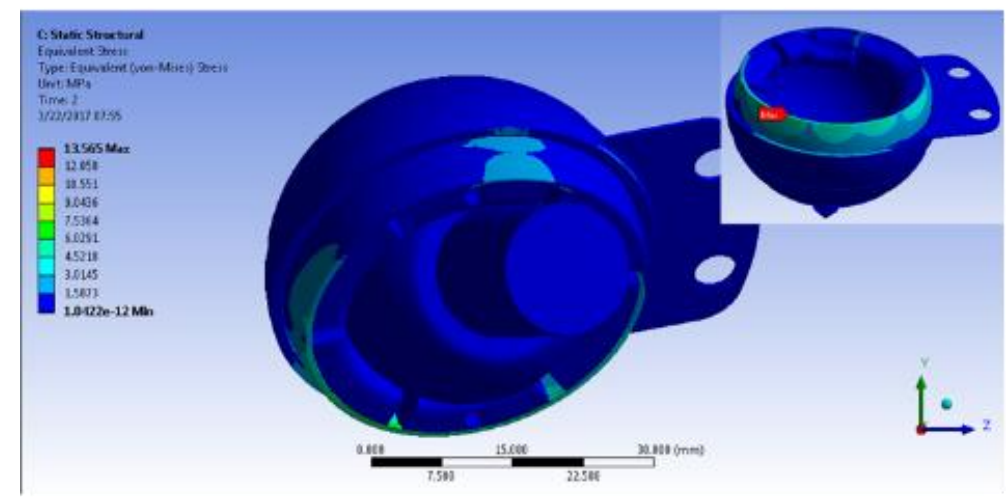

Gambar 8. Kontur tegangan von Mises pada artificial hip joint

\section{Kesimpulan}

Dalam penelitian ini, performa artificial hip joint dianalisis dengan menggunakan metode yang lebih komprehensif, yaitu fluid-structure interaction (FSI). Metode ini selain menghitung mekanika solid, memungkinkan pengaruh synovial fluid sebagai pelumas alami terhadap performa pelumasan dapat dilakukan dengan mekanika fluida. Dari hasil simulasi yang sudah dijelaskan di atas dapat disimpulkan beberapa hal, diantaranya adalah pemodelan posisi gerakan salat pada artificial hip joint dengan memperhitungkan keberadaan cairan synovial fluid sangat penting dikarenakan adanya perbedaan yang signifikan terkait tegangan von Mises dan terjadinya impingement. Selain itu, hasil simulasi menunjukkan bahwa jika dibandingkan dengan hasil penelitian tanpa synovial fluid, tren penurunan tegangan von Mises pada present study jauh lebih kecil. Hal ini menunjukkan bahwa synovial fluid dapat mengurangi tegangan yang terjadi serta membuktikan bahwa keberadaan cairan synovial fluid memiliki pengaruh yang signifikan terhadap kinerja artificial hip joint. Adapun gerakan rukuk memiliki deformasi yang relatif cukup kecil jika dibandingkan dengan toleransi (clearance) yang ada, sehingga resiko impingement saat rukuk sangat kecil.

\section{Daftar Pustaka}

[1] Kiefer H., 2007, "Current Trends in Total Hip Arthroplasty in Europe and Experiences with the Bicontact Hip System," In: Sofue M., Endo N. (eds) Treatment of Osteoarthritic Change in the Hip. Springer, Tokyo.

[2] Legowo, A.,B., 2015, "Simulasi dan Evaluasi Acetabular Liner dan Femoral Head Total Hip Arthoplasty Model Undip pada Gerakan Shalat Menggunakan Metode Elemen Hingga," Tugas Akhir S1 Teknik Mesin. Universitas Diponegoro.

[3] Kluess, D., Martin, H., Mittelmeier, W., Schmitz, K.P. and Bader, R., 2007, "Influence of Femoral Head Size on Impingement, Dislocation and Stress Distribution in Total Hip Replacement," Medical engineering \& physics, 29(4): 465-471. 
[4] Dhaneswara, Y.A., 2016, "Analisis Pengaruh Clearance Terhadap Keausan dan Impingement Gerakan Salat pada Sendi Panggul Buatan Produk Undip Tipe Bipolar Menggunakan Metode Elemen Hingga,” Tugas Akhir S1 Teknik Mesin, Universitas Diponegoro, Semarang.

[5] Gapa, A.E.R., 2017, "Biomekanika Sendi Panggul Saat Berjalan Dan Salat," Tugas Akhir S1 Teknik Mesin. Universitas Diponegoro.

[6] Saputra, E., Anwara, I.B., Ismail, R., Jamari, J. dan van der Heide, E., 2014, "Numerical Simulation of Artificical Hip Joint Movement for Western and Japanese-Style Activities", Jurnal Teknologi (Sciences \& Engineering) 66: 53-58.

[7] Gao, L., Yang, P., Dymond, I., Fisher, J. Dan Jin, Z., 2010, "Effect of Surface Texturig on the Elastohydrodynamic Lubrication Analysis of Metal-on-Metal Hip Implants”, Tribology International 43: 18511860.

[8] Jhurani, S.M., Higgs, C.F. 2010. "An Elastohydrodynamic Lubrication (EHL) Model of Wear Particle Migration in an Artificial Hip Joint", Tribology International 43 (8):1326-1338.

[9] Mattei, L., DiPuccio, F., Piccigallo, B., Ciulli, E, 2011, "Lubrication and Wear Modelling of Artificial Hip Joints: A Review", Tribology International 44: 532-549.

[10] Vrbka, M., Nečas, D., Hartl, M., Křupka, I., Urban, F., Gallo, J. 2015, "Visualization of Lubricating Films Between Artificial Head and Cup with Respect to Real Geometry", Biotribology 1-2: 61-65.

[11] Tauviqirrahman, M., Muchammad, Bayuseno, A.P., Ismail, R., Saputra, E. dan Jamari, J. 2016. "Estimation of Appropriate Lubricating Film Thickness in Ceramic-On-Ceramic Hip Prostheses", American Institute of Physic (AIP) Conference Proceedings 1725: 020090-1-020090-4. 